\title{
Comparative study of the effects of biphenyl and Kanechlor-400 on the respiratory and energy linked activities of rat liver mitochondria
}

\author{
Y NISHIHARA
}

From the Department of Medical Biology, Kochi Medical School, Kohasu, Okocho, Nangoku-shi, Kochi 781-51, Japan

ABSTRACT A comparative study of the effects of biphenyl and Kanechlor-400 (KC-400) on the respiratory and energy linked activities of rat liver mitochondria was made, and some differences in effects caused by the chlorination of biphenyl were clarified. The inhibition of state 3 respiration with succinate by biphenyl was less than that observed with $\alpha$-ketoglutarate/malate. By contrast, KC-400 exhibited the opposite trend; state 3 respiration with succinate was more sensitive to inhibition than that observed with $\alpha$-ketoglutarate/malate. Thus the inhibition of state 3 respiration with $\mathrm{NAD}^{+}$-linked substrate was decreased, whereas the inhibition of state 3 respiration with succinate was increased by the chlorination of aromatic rings. Biphenyl also instantaneously stimulated state 4 respiration. The extent of stimulation with succinate by biphenyl was larger than with $\alpha$-ketoglutarate-malate. On the other hand, there was about a 1-2 minute lag period before stimulation of state 4 respiration by KC-400 became obvious. Furthermore, state 4 respiration in the presence of $\alpha$-ketoglutarate/malate was more intensely stimulated by $\mathrm{KC}-400$ than by succinate. Biphenyl and $\mathrm{KC}-400$ dissipated the membrane potential across the mitochondrial membranes. The dissipation of membrane potential by biphenyl was instan-? taneous whereas that caused by $\mathrm{KC}-400$ was preceded by a lag period (1-2 min). Biphenyl and $\mathrm{KC}-400$ altered the permeability properties of mitochondrial membranes as evidenced by the release of endogenous $\mathrm{K}^{+}$. The release of $\mathrm{K}^{+}$due to biphenyl was instantaneous but $\mathrm{KC}-400$ induced $\mathrm{K}^{+}$-release was preceded by a lag period (1-2 min). Thus membrane perturbation by biphenyl was faster than that induced by $\mathrm{KC}-400$. Therefore, it is clear that the chlorination of aromatic rings delays the perturbation in the state of membrane lipids.

Polychlorinated biphenyls (PCBs) are highly stable compounds that have been used in various products and industrial processes. Owing to their resistance to degradation, PCBs are accumulated by organisms at all levels of the food chains in a manner similar to DDT. ${ }^{2}$

The possibility that cell membrane may be the site of toxic effects is being increasingly emphasised ${ }^{3}$ and, because of their lipophilic character, PCBs may act at the membrane level. The mitochondrial inner membrane possesses the energy transducing functions, and mitochondrial oxidative phosphorylation is responsible for supplying over $95 \%$ of the total

Received 6 February 1984 Accepted 27 February 1984
ATP requirement in eukaryotic cells. ${ }^{4}$

Several studies of the interaction of chlorinated hydrocarbon pesticides with mitochondria have been made and it has been reported that chlordecone $^{5}$ and DDT ${ }^{6}$ may affect the energy transducing reaction of rat liver mitochondria. In a previous paper PCBs (Kanechlor-400) were shown as both an inhibitor and an uncoupler of oxidative phosphorylation in rat liver mitochondria ${ }^{7}$; Kanechlor400 (KC-400) inhibits succinate dehydrogenase and the CoQ-cytochrome $c$ region of the electron transport chain. While investigating the effects of PCBs on mitochondria, biphenyl (the parent compound of PCBs) was found to affect mitochondrial energy transducing functions in a manner that differed from that of PCBs.

In the present paper a comparative study of the 
effects of biphenyl and $\mathrm{KC}-400$ on the respiratory and energy linked activities of rat liver mitochondria is made, and some differences in the effects caused by the chlorination of aromatic rings are clarified. Biphenyl inhibits the oxidation of NAD ${ }^{+}$linked substrate more strongly than succinate oxidation. By contrast, chlorinated product (KC-400) has an opposite effect such that succinate oxidation is more sensitive to inhibition by KC-400 than oxidation of NAD ${ }^{+}$linked substrate.

\section{Materials and methods}

Biphenyl was obtained from the Tokyo Kasei Kogyo Co, Ltd (Tokyo, Japan) and KC-400 (main components tetrachlorobiphenyls) was purchased from Kanegafuchi Chemical Industry Co, Ltd (Osaka, Japan); both were dissolved in ethanol. Adenosine-5'-diphosphate (ADP) was purchased from the Sigma Chemical Co (St Louis, MO). Other chemicals were commercial products of reagent grade.

Liver mitochondria were isolated from male Wistar rats $(200-300 \mathrm{~g})$ in $0.25 \mathrm{M}$ sucrose, $5 \mathrm{mM}$ Tris$\mathrm{HCl}(\mathrm{pH} \mathrm{7.4)}$, and $0.1 \mathrm{mM}$ EDTA by the method of Hogeboom. ${ }^{8}$ The last washing was carried out in an EDTA free medium. Mitochondrial protein was assayed by the Biuret method, ${ }^{9}$ using bovine serum albumin as a standard.

The polarographic measurements of oxygen consumption and measurements of the effects of the test compounds on respiration rates were as described by Nishihara.' The $2 \mathrm{ml}$ reaction mixture used for polarographic measurements consisted of $200 \mathrm{mM}$ sucrose; $20 \mathrm{mM} \mathrm{KCl} ; 3 \mathrm{mM} \mathrm{MgCl}$; $5 \mathrm{mM}$ potassium phosphate (pH 7.4); $5 \mathrm{mM}$ succinate or $5 \mathrm{mM}$ $\alpha$-ketoglutarate/ $5 \mathrm{mM}$ malate as respiratory sub- strates; and $1 \mathrm{mg} / \mathrm{ml}$ of mitochondria. Measurements were carried out at $25^{\circ} \mathrm{C}$.

$\mathrm{K}^{+}$effluxes were monitored at $25^{\circ} \mathrm{C}$ with a $\mathrm{K}^{+}$selective electrode in a water jacketed, thermostatically controlled vessel equipped with a magnetic stirrer. Calibration of the electrode was performed by multiple additions of known amounts of $\mathrm{KCl}$ before each experiment. The reaction mixture consisted of $150 \mathrm{mM}$ choline chloride, $10 \mathrm{mM}$ Tris- $\mathrm{HCl}$ (pH 7.4), and $1 \cdot \mathrm{mg} / \mathrm{ml}$ of mitochondria in a final volume of $3 \mathrm{ml}$.

The membrane potential across the mitochondrial membranes was monitored at $25^{\circ} \mathrm{C}$ with a tetraphenylphosphonium ion $\left(\mathrm{TPP}^{+}\right)$electrode constructed according to Kamo et al. ${ }^{10}$ The reaction mixture was the same medium as used for the measurement of oxygen uptake plus $10 \mu \mathrm{M} \mathrm{TPP}+$ in a final volume of $2 \mathrm{ml}$. TPP + at this concentration had no effect on mitochondrial state 3 and 4 respirations. Calibration of the electrode was performed by multiple addition of known amounts of TPP+ before each experiment.

In this study all experiments were repeated at least three times, and the figures represent one of the typical examples.

\section{Results}

Table 1 shows the effects of biphenyl and KC-400 on the rate of succinate oxidation in rat liver mitochondria. State 3 respiration was slightly inhibited by biphenyl with only $33 \%$ inhibition even at $60 \mu \mathrm{g} / \mathrm{ml}$. By contrast, $\mathrm{KC}-400$ caused strong inhibition, $13 \mu \mathrm{g} / \mathrm{ml}$ inducing $50 \%$ inhibition. State 4 respiration was greatly stimulated by biphenyl with a fivefold increase at a concentration range of 30-60 $\mu \mathrm{g} / \mathrm{ml}$, but the extent of stimulation by $\mathrm{KC}-400$ was

Table 1 Effects of biphenyl and $K C-400$ on the rate of succinate oxidation

\begin{tabular}{|c|c|c|c|c|}
\hline \multirow{3}{*}{$\begin{array}{l}\text { Concentration } \\
(\mu g / m l)\end{array}$} & \multicolumn{4}{|c|}{ Oxygen consumption (natoms/min/mg protein) } \\
\hline & \multicolumn{2}{|l|}{ Biphenyl } & \multicolumn{2}{|l|}{$K C-400^{*}$} \\
\hline & State 3 & State 4 & State 3 & State 4 \\
\hline $\begin{array}{l}\text { Control } \\
5 \\
10 \\
20 \\
30 \\
40 \\
50 \\
60\end{array}$ & $\begin{aligned} 101 \cdot 5 & \pm 3 \cdot 2 \\
101 \cdot 0 & \pm 3 \cdot 1 \\
98 \cdot 8 & \pm 4 \cdot 0 \\
73.3 & \pm 1 \cdot 2^{* * *} \\
70.3 & \pm 2 \cdot 4^{* * *} \\
69.7 & \pm 2.9^{* * *} \\
69.0 & \pm 3 \cdot 7^{* * *} \\
67.3 & \pm 5 \cdot 2^{* * *}\end{aligned}$ & $\begin{aligned} 21 \cdot 3 & \pm 2 \cdot 1 \\
22.7 & \pm 1 \cdot 9 \\
28.0 & \pm 1 \cdot 4^{*} \\
47.3 & \pm 6 \cdot 2^{* *} \\
94.0 & \pm 3 \cdot 7^{* * *} \\
97 \cdot 0 & \pm 3 \cdot 7^{* * *} \\
100 \cdot 6 & \pm 1 \cdot 9^{* * *} \\
97 \cdot 0 & \pm 3 \cdot 7^{* * *}\end{aligned}$ & $\begin{array}{r}103.3 \pm 3.4 \\
75 \cdot 1 \pm 6 \cdot 5^{* *} \\
52.3 \pm 11 \cdot 6^{* *} \\
42.0 \pm 8 \cdot 8^{* * *} \\
25.0 \pm 5.1^{* * *} \\
19.3 \pm 2.4^{* * * *}\end{array}$ & $\begin{array}{l}20.0 \pm 0.8 \\
20.0 \pm 0.8 \\
20.0 \pm 0.8 \\
24.4 \pm 0.8^{*} \\
24.0 \pm 2.1^{*} \\
17.5 \pm 3.5\end{array}$ \\
\hline
\end{tabular}

The effects on state 3 respiration were measured by the oxygen consumption after the addition of $150 \mu \mathrm{M}$ ADP exactly three minutes after the introducton of test compound. Effects on state 4 respiration were measured by the oxygen consumption exactly three minutes after the introduction of test compound to the reaction medium during state 4 respiration after the addition of $150 \mu \mathrm{M}$ ADP. Control experiments were carried out with equivalent volume of solvent (ethanol). The values represent the mean $\pm S D$ of three experiments.

*KC-400 data as reported by Nishihara.?

Significantly different from the control: ${ }^{*} p<0.05,{ }^{* *} p<0.01,{ }^{* * *} p<0.001$ 
Table 2 Effects of biphenyl and $K C-400$ on the rate of $\alpha$-ketoglutarate/malate oxidation

\begin{tabular}{|c|c|c|c|c|}
\hline \multirow{3}{*}{$\begin{array}{l}\text { Concentration } \\
(\mu \mathrm{g} / \mathrm{ml})\end{array}$} & \multicolumn{4}{|c|}{ Oxygen consumption (natoms/min/mg protein) } \\
\hline & \multicolumn{2}{|l|}{ Biphenyl } & \multicolumn{2}{|l|}{$K C-400^{*}$} \\
\hline & State 3 & State 4 & State 3 & State 4 \\
\hline $\begin{array}{l}\text { Control } \\
5 \\
10 \\
20 \\
30 \\
40 \\
50 \\
60\end{array}$ & $\begin{array}{l}44.0 \pm 1.6 \\
41.0 \pm 1.4 \\
40.6 \pm 1.9 \\
23.7 \pm 1.9^{* * *} \\
18.3 \pm 0.5^{* * *} \\
16.3 \pm 1.2^{* * *} \\
13.0 \pm 1.6^{* * *} \\
11.3 \pm 0.9^{* * *}\end{array}$ & $\begin{array}{c}6.7 \pm 0.9 \\
7.0 \pm 1.4 \\
9.7 \pm 1.7 \\
19.7 \pm 2.6^{* *} \\
16.3 \pm 2.1^{* *} \\
14.0 \pm 0.8^{* *} \\
11.3 \pm 1.7^{*} \\
9.6 \pm 0.5^{*}\end{array}$ & $\begin{array}{l}48 \cdot 0 \pm 2 \cdot 0 \\
48 \cdot 0 \pm 2 \cdot 0 \\
46.6 \pm 0 \cdot 1 \\
43.4 \pm 0.9 \\
37 \cdot 5 \pm 0.5^{* *} \\
31 \cdot 7 \pm 2 \cdot 3^{* *} \\
27 \cdot 0 \pm 1 \cdot 5^{* * *} \\
24 \cdot 1 \pm 1 \cdot 1^{* *}\end{array}$ & $\begin{array}{c}6.8 \pm 0.8 \\
8.0 \pm 1.0 \\
11.3 \pm 1.6 \\
30.8 \pm 2.3^{* * *} \\
29.1 \pm 1.7^{* * *} \\
20.3 \pm 1.5^{* *} \\
17.9 \pm 1.8^{* *} \\
15.8 \pm 0.8^{* *}\end{array}$ \\
\hline
\end{tabular}

The effects of test compound on state 3 and state 4 respiration were measured as for the legend in table 1 . The values represent the mean \pm SD of three experiments.

Significantly different from the control: ${ }^{*} p<0.05,{ }^{* *} p<0.01,{ }^{* * *} p<0.001$.

small. These facts indicate that the inhibitory effect on state 3 respiration is increased, whereas the stimulatory action on state 4 respiration is greatly diminished by the chlorination of aromatic rings, when succinate is the substrate.

Table 2 shows the effects of biphenyl and KC-400 on the oxygen consumption with $\alpha$-ketoglutarate/malate as the substrate. State 3 respiration was progressively inhibited by biphenyl. The amount of biphenyl required to produce $50 \%$ inhibition was $22 \mu \mathrm{g} / \mathrm{ml}$. At $60 \mu \mathrm{g} / \mathrm{ml}$, biphenyl inhibited about $75 \%$ of control respiration. By contrast, the inhibition of state 3 respiration by KC- 400 was relatively weak, when compared with that induced by biphenyl. State 4 respiration was stimulated by

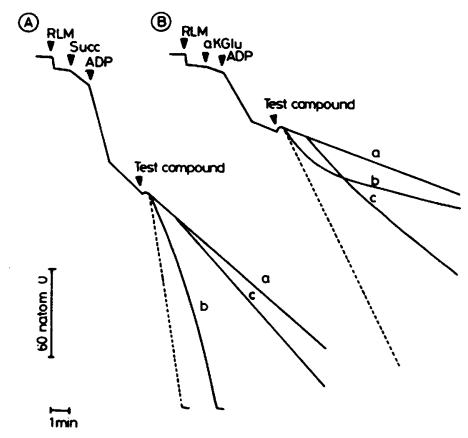

Fig 1 Representative polarographic traces of effects of biphenyl and $K C-400$ on state 4 respiration of mitochondria. The traces were recorded either with $5 \mathrm{mM}$ succinate (Succ, trace A) or with $5 \mathrm{mM} \alpha$-ketoglutarate/5 $m M$ malate ( $\alpha K G$ lu, trace $B$ ). In both trace $A$ and $B,(a)$ control; (b) biphenyl, $30 \mu \mathrm{g} / \mathrm{ml}$; (c) $\mathrm{KC}-400,30 \mu / \mathrm{ml}$; dotted line, DNP (25 $\mu M)$-induced respiration; rat liver mitochondria (RLM), $1 \mathrm{mg} / \mathrm{ml} ; A D P, 150 \mu M$; temp, $25^{\circ} \mathrm{C}$. both biphenyl and $\mathrm{KC}-400$, but the extent of stimulation due to biphenyl was less than that caused by $\mathrm{KC}-400$. From these facts it is obvious that the inhibitory effect on state 3 respiration is diminished, and the stimulatory action on state 4 respiration is increased by the chlorination of aromatic rings in the presence of $\alpha$-ketoglutarate/malate as the substrate.

Figure 1 shows the representative polarographic traces that depict the time course of the effects of biphenyl $(30 \mu \mathrm{g} / \mathrm{ml})$ and $\mathrm{KC}-400(30 \mu \mathrm{g} / \mathrm{ml})$ on state 4 respiration. Biphenyl stimulated state 48 respiration instantaneously in the presence of succinate in a manner similar to 2,4-dinitrophenol (DNP). With $\alpha$-ketoglutarate/malate as the substrate, biphenyl caused an initial stimulation and a

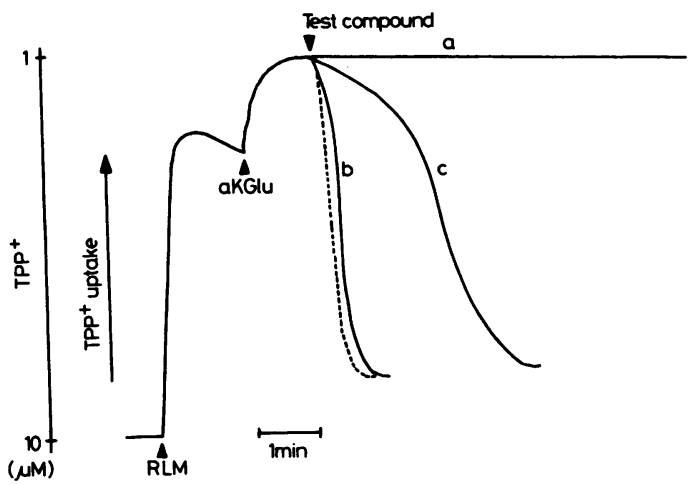

Fig 2 Comparison of effects of biphenyl and $K C-400$ on membrane potential of mitochondria monitored by uptake of $\mathrm{TPP}^{+}$. Rat liver mitochondria (RLM, $\left.1 \mathrm{mg} / \mathrm{ml}\right)$ were incubated at $25^{\circ} \mathrm{C}$ : (a) control; (b) biphenyl, $30 \mu \mathrm{g} / \mathrm{ml}$; (c) $K C-400,30 \mu \mathrm{g} / \mathrm{ml}$. Dotted line shows DNP (25 $\mu M$ )-induced $T P P^{+}$release. $\alpha K G L u$ indicates $5 \mathrm{mM}$ $\alpha$-ketoglutarate/5 $\mathrm{mM}$ malate. 


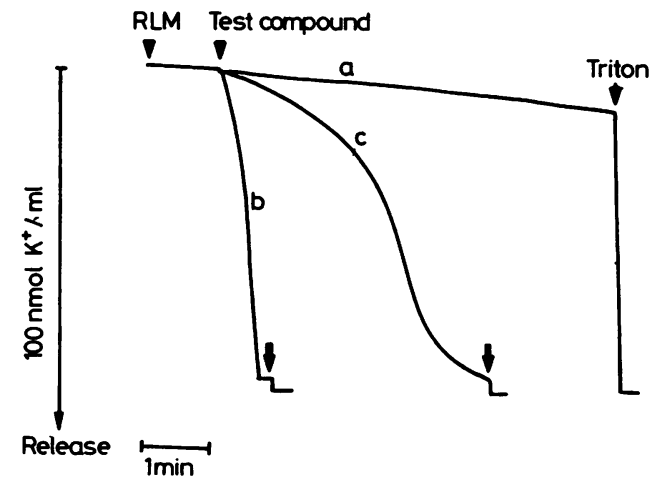

Fig 3 Comparison of effects of biphenyl and $K C-400$ on $\mathrm{K}^{+}$-release from mitochondria. Rat liver mitochondria (RLM, $1 \mathrm{mg} / \mathrm{ml}$ ) were incubated at $25^{\circ} \mathrm{C}$ : (a) control; (b) biphenyl, $30 \mu \mathrm{g} / \mathrm{ml} ;$ (c) $\mathrm{KC}-400,30 \mu \mathrm{g} / \mathrm{ml}$. At end of each run, Triton $X-100$ at a final concentration of $0.1 \%$ was added to obtain complete release of $\mathrm{K}^{+}$.

subsequent inhibition in the rate of state 4 respiration. By contrast, the stimulation induced by $\mathrm{KC}-400$ was preceded by a lag period (1-2 min), the duration of which was dependent on the KC-400 concentration. The stimulation by $\mathrm{KC}-400$ was more effective with $\alpha$-ketoglutarate/malate than with succinate as substrate.

Figure 2 shows the effects of biphenyl $(30 \mu \mathrm{g} / \mathrm{ml})$ and $\mathrm{KC}-400(30 \mu \mathrm{g} / \mathrm{ml})$ on the membrane potential across mitochondrial membranes. An addition of substrate ( $\alpha$-ketoglutarate/malate) to a mitochondrial suspension caused an uptake of TPP+ from the reaction medium into the mitochondria (formation of membrane potential). A subsequent addition of biphenyl or $\mathrm{KC}-400$ induced a concentration dependent release of incorporated TPP+ into the incubation medium (dissipation of membrane potential). Biphenyl caused an instantaneous release similar to DNP. On the other hand, the release induced by $\mathrm{KC}-400$ was preceded by a lag period. Therefore, both biphenyl and KC-400 collapse the membrane potential, although in a different manner. That is, biphenyl collapses membrane potential instantaneously, but a lag period $(1-2 \mathrm{~min})$ is required before the dissipation by $\mathrm{KC}-400$ becomes obvious.

Figure 3 shows the rates of release of endogenous $\mathrm{K}^{+}$from mitochondria treated with biphenyl (30 $\mu \mathrm{g} / \mathrm{ml})$ or $\mathrm{KC}-400(30 \mu \mathrm{g} / \mathrm{ml})$. Neither biphenyl nor KC-400 caused a $\mathrm{K}^{+}$-release until a concentration of $10 \mu \mathrm{g} / \mathrm{ml}$ was achieved. Above this concentration these agents induced the release of $\mathrm{K}^{+}$in a concentration dependent manner (data not shown). The release of $\mathrm{K}^{+}$induced by biphenyl was instantane- ous whereas the $\mathrm{K}^{+}$-released caused by $\mathrm{KC}-400$ was preceded by a lag period.

\section{Discussion}

The inhibition by biphenyl of state 3 respiration with a succinate substrate was less than that observed with $\alpha$-ketoglutarate/malate. By contrast, KC-400 exhibited the opposite trend; state 3 respiration with succinate was more sensitive to inhibition than that observed with $\alpha$-ketoglutarate/malate. In the presence of ascorbate/ $\mathbf{N}, \mathbf{N}, \mathbf{N}^{\prime}, \mathbf{N}^{\prime}$-tetramethyl-p-phenylenediamine (TMPD), state 3 respiration was scarcely inhibited, while state 4 respiration was stimulated by biphenyl and KC-400 (data not shown). The inhibition of state 3 respiration is generally considered to reflect an interference with electron transport. Although the site of action of biphenyl in the electron transport chain remains to be elucidated, the facts mentioned above indicate that the NADH-CoQ region of the electron transport chain is more sensitive to inhibition by biphenyl than the succinate-CoQ region. The previous paper showed that KC-400 selectively inhibits succinate dehydrogenase and the CoQ-cytochrome $c$ region whereas the NADH-CoQ region of the electron transport chain was almost completely unaffected.' Thus the chlorination of biphenyl alters the manner in which the electron transport chain is blocked. That is, blockage of the NADH-CoQ region is diminished, whereas blockage of the succinate-CoQ region is increased by the chlorination of aromatic rings.

Biphenyl and KC-400 also stimulated state 4 respiration. This may be explained by an uncoupling action. Additional evidence that these agents act as uncouplers is the release of oligomycin inhibited state 3 respiration (data not shown), and the dissipation of the membrane potential (fig 2). When succinate was used as the substrate, the full expression of the uncoupling action of biphenyl could be achieved, since the inhibition of the electron transport chain was not so great. With $\alpha$-ketoglutarate/malate, however, the uncoupling action of biphenyl was masked in a concentration and time dependent manner because of the increased inhibition of the electron transport chain. By contrast, the full expression of the uncoupling action due to $\mathrm{KC}-400$ could be achieved with $\alpha$-ketoglutarate/malate. When succinate was the substrate, the uncoupling action of $\mathrm{KC}-400$ was masked because of the increased inhibition of the electron transport chain (fig 1).

According to the chemiosmotic view," protonophoric uncouplers such as DNP and 3chloro-carbonylcyanide phenylhydrazone (CCCP) 
shuttle protons across the membrane in a neutral acid form, which is membrane permeable, donating protons to the matrix side. The anionic conjugate base thus produced moves back electrophoretically to the positively charged outside from the negatively charged inside of the mitochondrial membrane. In the complete cycle the protonophoric uncouplers dissipate the $\mathrm{H}^{+}$gradient and the membrane potential across the mitochondrial membranes. Thus the dissipation of the membrane potential across the membrane is generally regarded as decisive for the exhibition of uncoupling. The mitochondria treated with DNP in this study also caused the dissipation of the membrane potential (fig 2). Biphenyl dissipated the membrane potential instantaneously in a manner similar to DNP (fig 2). This was also the case with the manner in which biphenyl stimulated state 4 respiration. By contrast there was a time lag for the dissipation of the membrane potential by $\mathrm{KC}-400$ stimulated state 4 respiration-that is, a 1-2 minute lage period was required before the stimulation of state 4 respiration became obvious.

With a protonophoric uncoupler, dissipation of the membrane potential is performed by carrying protons across the membrane with an acid dissociable group within the molecule. Biphenyl and KC-400 (a mixture of chlorinated biphenyls) do not, however, possess an acid dissociable group. These agents dissipate the membrane potential by increasing the permeability of the inner membranes of the mitochondria to ions as evidenced by the $\mathrm{K}^{+}$-release from the mitochondria (fig 3). As indicated by the $\mathrm{K}^{+}$-release (fig 3 ), the increase in ion permeability produced by biphenyl is instantaneous, leading to the immediate dissipation of the membrane potential (fig 2). On the other hand, $\mathrm{KC}-400$ required a time lag to induce $\mathrm{K}^{+}$-release from the mitochondria, and a time lag was also required for $\mathrm{KC}-400$ to dissipate the membrane potential. The $\mathrm{K}^{+}$-release from the mitochondria is the result of a perturbation in the lipid bilayer of the inner membranes. Therefore, clearly, the chlorination of aromatic rings delays the perturbation in the structure of membrane lipids.

On the toxicity of PCBs on mitochondria, Stotz and Greichus reported alterations in the shape of liver mitochondria from the white pelican by in vivo treatment with PCBs. ${ }^{12}$ That is, mitochondria from the PCB treated white pelican were rounded and swollen instead of long and slender as in untreated animals. Jonsson et al reported that mitochondrial changes compatible with necrosis were found in the livers of rats fed with PCBs. ${ }^{13}$ These phenomena may be attributed to an interference with the oxidative production of ATP.

I thank Professor Kozo Utsumi for many helpful discussions and critical reading of the manuscript.

\section{References}

' Reisebrough RW, Reiche P, Peakall DB, Herman SG, Kirven MN. Polychlorinated biphenyls in the global ecosystem. Nature 1968;220:1098-102.

2 Peakall DB. Polychlorinated biphenyls, occurrence and biological effects. Residue Rev 1972;44:1-21.

${ }^{3}$ Pritchard JB. Toxic substances and cell membrane function. Fed Proc 1979;38:2220-5.

${ }^{4}$ Erecinska M, Wilson DF. Regulation of cellular energy metabolism.J Membrane Biol 1982;70:1-14.

${ }^{5}$ Manring JA, Moreland DE. Effects of chlordecone on isolated rat liver mitochondria. Toxicol Appl Pharmacol 1981; 59:483-8.

${ }^{-}$Ohyama T, Takahashi T, Ogawa H. Effects of dichlorodiphenyltrichloroethane and its analogues on rat liver mitochondria. Biochem Pharmacol 1982;31:397-404.

' Nishihara Y. Effects of polychlorinated biphenyls (Kanechlor400) on isolated rat liver mitochondria. Arch Environ Contam Toxicol 1983; 12:517-22.

${ }^{8}$ Hogeboom GH. Fractionation of cell component of animal tissues. Methods Enzymol 1955;1:16-9.

${ }^{9}$ Gornall AG, Bardawill CJ, David MM. Determination of proteins by means of biuret reaction. J Biol Chem 1949; 177:751-66.

${ }^{10}$ Kamo N, Muratsugu M, Hongoh R, Kobatake Y. Membrane potential of mitochondria measured with an electrode sensitive to tetraphenylphosphonium and relationship between proton electrochemical potential and phosphorylation potential in steady state. J Membrane Biol 1979;49:105-21.

"Mitchell P. Chemiosmotic coupling in oxidative and photosynthetic phosphorylation. Bodmin, UK: Glynn Research Ltd, 1966:135-56.

${ }_{12}$ Stotz IJ, Greichus YA. The effects of a polychlorinated biphenyl (Aroclor 1254) on the white pelican, ultrastructure of hepatocytes. Bull Environ Contam Toxicol 1978;19:319-25.

13 Jonsson HT Jr, Walker EM Jr, Greene WB, Hughson MD, Hennigar GR. Effect of prolonged exposure to dietary DDT and PCB on rat liver morphology. Arch Environ Contam Toxicol 1981; 10: 171-83. 